\title{
Evaluation of the forced expiration technique as an adjunct to postural drainage in treatment of cystic fibrosis
}

\author{
J A PRYOR, B A WEBBER, M E HODSON, J C BATTEN
}

British Medical fournal, 1979, 2, 417-418

\section{Summary and conclusions}

Sixteen patients with cystic fibrosis were treated with conventional physiotherapy aided by an assistant. The results were compared with those produced by physiotherapy using the forced expiration technique without an assistant. The forced expiration technique cleared more sputum in less time than conventional physiotherapy. A second study showed that an assistant did not further improve the results obtained by the patient performing the forced expiration technique himself.

These findings mean that patients with cystic fibrosis who have had to rely on the help of others for their home treatment may now perform more effective treatment without help. The forced expiration technique might also be helpful for patients with chronic bronchitis, asthma, or bronchiectasis.

\section{Introduction}

The value of chest physiotherapy in clearing bronchial secretions in conjunction with postural drainage in patients producing more than $30 \mathrm{ml}$ of sputum per day was established by Cochrane et al. ${ }^{1}$ Techniques commonly used to aid gravity in removing secretions are breathing exercises, vibratory shaking of the chest wall, percussion, and coughing. ${ }^{2}$ Some physiotherapists also use forced expiration (huffing). A technique of forced expirations, interspersed with carefully controlled diaphragmatic breathing, has been used by Thompson ${ }^{3}$ in clearing bronchial secretions in asthma.

Many patients with cystic fibrosis carry out postural drainage at home, relying on a relative or friend to do percussion and chest shaking. If a method could be found to provide efficient bronchial clearance without the aid of an assistant this would be a considerable advantage for these patients. We therefore compared the effectiveness of conventional, assisted postural drainage with a technique of self-postural drainage using the forced expiration technique in patients with cystic fibrosis. A further study was undertaken to find out whether pcstural drainage, using the forced expiration technique, would be enhanced by additional percussion and chest shaking from an assistant.

\section{Patients and methods}

PART 1

Eighteen patients with cystic fibrosis entered the trial. All patients admitted with cystic fibrosis, excluding those admitted for terminal care, were eligible for the trial. Two patients were later withdrawn, one because he developed a pneumothorax and another

\section{Brompton Hospital, London SW3 6HP}

J A PRYOR, MNZSP, SRP, senior physiotherapist

B A WEBBER, MCSP, SRP, assistant superintendent physiotherapist

$M$ E HODSON, MD, MRCP, clinica! senior lecturer in medicine, and honorary consultant physician

J C BATTEN, MD, FRCP, consultant physician because he produced too little sputum for accurate assessment. Sixteen patients ( 8 men, 8 women; mean age 20.5 years (range $14-28$ ) completed the first part of the study, and all were studied for four days as near as possible to the date of discharge. The diagnosis of cystic fibrosis was established on the basis of malabsorption, chronic bronchopulmonary infection, and a sweat sodium concentration of over $70 \mathrm{mmol}(\mathrm{mEq}) / 1$. Each patient had been admitted to hospital with an acute exacerbation of his bronchopulmonary infection and required intensive physiotherapy and antibiotics. Thirteen patients needed intravenous antibiotics, two had only oral antibiotics, and one had none.

Physiotherapy was carried out using two different treatment regimens. Treatment A consisted of postural drainage using expansion breathing exercises, coughing, and percussion by the patient himself combined with chest percussion and shaking by a physiotherapist. Treatment B consisted of postural drainage using the forced expiration technique, with expansion breathing exercises, coughing, and percussion and chest compression by the patient alone.

The forced expiration technique (FET) consists of one or two huffs (forced expirations), from mid-lung volume to low lung volume, followed by a period of relaxed, controlled diaphragmatic breathing. Bronchial secretions mobilised to the upper airways are then expectorated and the process is repeated until maximal bronchial clearance is obtained. The patient can reinforce the forced expiration by selfcompression of the chest wall using a brisk adduction movement of the upper arm.

Each patient was studied for four days: the first two days included treatments $A$ and $B$ in random order and the second two days included treatments $A$ and $B$, again in random order. To maintain maximal bronchial clearance 12 patients needed treatment four times during the day, three needed three treatments, and one only two treatments. In addition, and as necessary, the patients carried out postural drainage themselves in the evening and early morning. Each patient was positioned for drainage of his affected segments and these same areas were treated for the four days. The postural drainage session was continued until the patient felt that the area was clear of secretions and this subjective evaluation was confirmed by the physiotherapist. Three physiotherapists took part in the treatment sessions throughout the study.

Before the first treatment session each day and 30 minutes after its completion forced expiratory volume in one second $\left(\mathrm{FEV}_{1}\right)$ and forced vital capacity (FVC), were measured with a Vitalograph and peak expiratory flow rate (PEFR) with a Wright peak flow meter. The weight of sputum was measured using a Mettler $P 1200$ balance during each treatment session and up to 30 minutes after completion and between treatment sessions. The time taken for each treatment session was also noted.

PART 2

Eight patients ( 5 men, 3 women; mean age 23.9 years (14-34)) with cystic fibrosis took part in the second part of the study. Seven patients had been admitted to hospital because of acute exacerbation of bronchopulmonary infection and one for gynaecological investigations. Each patient underwent two physiotherapy regimens: treatment $B$, as in the first part of the study, and treatment $C$, which consisted of postural drainage using forced expiration combined with chest shaking and percussion by a physiotherapist.

The Wilcoxon matched pairs, signed rank test was used for the statistical analysis of the results.

\section{Results}

The mean time spent having treatment, the weight of sputum produced and the rate of sputum production each day under treatments $A$ and $B$ are shown in table I. The average rate of sputum 
TABLE I-Mean (士SE of mean) time for sputum clearance, weight of sputum, and rate of sputum production during treatment sessions per day in first part of study

\begin{tabular}{|c|c|c|}
\hline Treatment & A & B \\
\hline $\begin{array}{l}\text { Time being treated }(\mathrm{min}) . \\
\text { Weight of sputum }(\mathrm{g}) \\
\text { Rate of sputum production } \\
\text { ( } \mathrm{mg} / \mathrm{min})\end{array}$ & $\begin{aligned} 127 \cdot 0 & \pm 8 \cdot 25(61-220) \\
45 \cdot 6 & \pm 5 \cdot 76(3 \cdot 0-131 \cdot 5) \\
358 \cdot 5 & \pm 36 \cdot 13(30-707)\end{aligned}$ & $\begin{aligned} 99 \cdot 4 & \pm 5 \cdot 76(41-173) \\
63 \cdot 1 & =6 \cdot 92(10 \cdot 1-187 \cdot 5) \\
652 \cdot 1 & \pm 64 \cdot 10(104-1654)\end{aligned}$ \\
\hline
\end{tabular}

clearance during the treatment sessions was calculated to give a direct measure of efficiency. On treatment $B$ the time for treatment was shorter $(0.01>P>0.005)$, the sputum weight greater $(0.025>P>0.01)$, and the rate of sputum production faster $(0.005>\mathbf{P}>0.001)$ than on treatment A. This pattern was consistent irrespective of the days on which the patients received the two treatments. After treatment $A$ there was a mean increase in $\mathrm{FEV}_{1}$ of $2^{\circ}, 0$ and after treatment $\mathrm{B}$ a mean increase of $6^{\circ}$.

Table II shows the results in the second part of the study. There were no significant differences between treatments $B$ and $C$.

Throughout both studies daily $\mathrm{FEV}_{1}, \mathrm{FVC}$, and PEFR recordings, together with a measurement of the total sputum produced in 24 hours, indicated that all patients either remained stable or improved.

TABLE II-Mean (_SE of mean) time for sputum clearance, weight of sputum, and rate of sputum production during treatment sessions per day in second part of study.

\begin{tabular}{|c|c|c|}
\hline Treatment & B & $\mathrm{C}$ \\
\hline $\begin{array}{l}\text { Time being treated }(\min ) . . \\
\text { Weight of sputum }(\mathrm{g}) \\
\text { Rate of sputum production } \\
(\mathrm{mg} / \mathrm{min})\end{array}$ & $\begin{array}{c}98 \cdot 3 \pm 5 \cdot 63(54-132) \\
46 \cdot 4 \pm 6 \cdot 20(12 \cdot 1-95 \cdot 7) \\
493 \cdot 1 \pm 69 \cdot 04(135-958)\end{array}$ & $\begin{array}{c}95 \cdot 3 \pm 5 \cdot 61(55-128) \\
44 \cdot 6 \pm 4 \cdot 61(18 \cdot 3-72 \cdot 6) \\
482 \cdot 2 \pm 52 \cdot 13(172-892)\end{array}$ \\
\hline
\end{tabular}

\section{Discussion}

A forced expiratory manoeuvre can be analysed using the concept of the equal pressure point, ${ }^{4}$ which is the point where the pressure within the airways is equal to the pleural pressure. During a forced expiratory manoeuvre there are forces tending to collapse or compress the airways downstream (towards the mouth) of the equal pressure point. This dynamic compression is an essential part of the mechanism of a huff or cough, which is therefore effective only at the compression points (choke points ${ }^{5}$ ) downstream of the equal pressure point. These choke points move upstream (towards the alveoli) as the lung volume decreases. ${ }^{*}$ Bronchoscopic studies of forced expiratory manoeuvres by de $\mathrm{Kock}^{6}$ and our own observations have shown a vibratory movement of the posterior membrane of the trachea and main bronchi moving down the bronchial tree with decreasing lung volume. This probably reflects compression of the downstream segment at the choke points.

On this basis Mead et al advocated a series of coughs without intervening inspirations to clear progressively "deeper" portions of the airways. ${ }^{4}$ Clinical observations suggest that performing a series of coughs without intervening inspirations is more exhausting than making a single, continuous huff down to the same lung volume. We therefore preferred to use the huff (or forced expiration), to which the same principles apply. To move distal secretions, the forced expiratory manoeuvre should therefore be performed at a low lung volume. It seems to be unnecessary to start this manoeuvre from a high lung volume, and we recommend that the huff should start at mid-lung volume and be continued down to low lung volume.

Forced expiration is often criticised for increasing airways obstruction. Our findings showed that neither of the techniques of physiotherapy that we used increased airways obstruction. Further work would be needed to show that the sputum produced by each method was of comparable viscosity and chemical composition.

The first part of our study showed that the forced expiration technique improved the efficiency of postural drainage in patients with cystic fibrosis.

The treatment days were randomised to allow for the expected improvement in the patient's condition. The use of a subjective, endpoint was valuable as the patient himself must develop an appreciation of when his chest is clear.

This finding means that patients who have been relying on help for their home treatment can now carry out more effective treatment independently using the forced expiration technique. Our study was primarily designed to assess a technique of postural drainage which the patient could perform at home. We do not suggest that the treatment of patients with an acute exacerbation of their bronchopulmonary infection would be equally effective without an assistant but that the efficiency of assisted postural drainage will be improved by using the forced expiration technique. The technique can probably also be applied with benefit to patients with retained bronchial secretions associated with chronic bronchitis, asthma, or bronchiectasis.

If it is to be effective, postural drainage should be an active exercise requiring the patient's full concentration throughout the session. Socially and economically it is important that postural drainage is carried out effectively in the shortest possible time and with the minimum of outside help. A patient who is fit enough to lead an independent life can treat himself efficiently if he is trained by a physiotherapist conversant with this method of postural drainage.

We thank Miss R A Parker, senior physiotherapist, who helped with some of the treatment, Miss D V Gaskell, superintendent physiotherapist, and other members of the physiotherapy department for their help. We are grateful to Dr M Green for advice concerning the physiological aspects of this method of treatment; to other members of the medical staff; and to Miss M Rehahn for statistical advice.

\section{References}

${ }^{1}$ Cochrane, G M, Webber, B A, and Clarke, S W, British Medical fournal, $1977,2,1181$.

2 Gaskell, D V, and Webber, B A, The Brompton Hospital Guide to Chest Physiotherapy, 3rd edn. Oxford, Blackwell Scientific, 1977.

3 Thompson, B J, New Zealand Fournal of Physiotherapy, 1973, 4, 11.

* Mead, J, et al, fournal of Applied Physiology, 1967, 22, 95.

5 Dawson, S V, and Elliott, E A, fournal of Applied Physiology, 1977, 43, 498.

6 de Kock, M A, Dynamic Bronchoscopy. Berlin, Springer-Verlag, 1977.

(Accepted 4 fuly 1979)

ONE HUNDRED YEARS AGO The P \& O steamer Pekin came into Greenock Harbour on April 3rd. She had sailed from London on March 28th, after a stay at that port of six days. One of the crew sickened with modified small-pox shortly after she left Gibraltar, on March 12th. He had quite recovered by the time the vessel arrived at London. Two more of the crew, however, showed symptoms of the disease on the voyage from London to the Clyde. The disease was, fortunately, very mild. On being reported, the cases were removed to Craigieknowes Hospital, along with a third who had suspicious symptoms of the disease, the man who had been first seized having been told off as an attendant on the sick. At the same time, the steamer was ordered to be taken out of the harbour to the roadstead, where she was thoroughly disinfected and the most of the remainder of the crew revaccinated. After lying at quarantine for fourteen days, and a second cleaning and disinfecting had been carried out, she was allowed to come into the harbour on April 17th. No fresh case occurred, and the men in the hospital recovered. The suspected case did not turn out to be small-pox. They all returned to their ship on May 2nd. The medical officer reports that the officers of the ship and the Company's representative have evinced the greatest eagerness to carry out the measures proposed by him for the prevention of the further spreading of the disease. In this respect they set an example worthy of imitation to all shipowners and shipmasters similarly situated. (British Medical fournal, 1879.) 